\title{
JUURNAL.RU
}

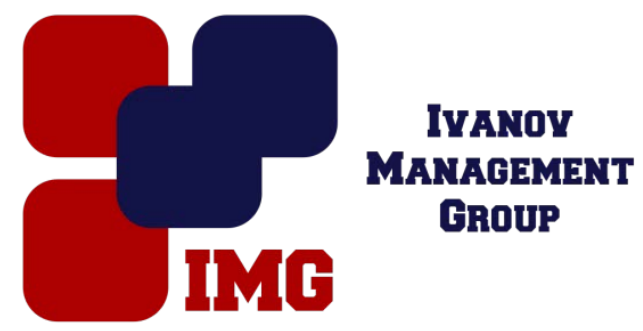

Бляблина Д.А. Государственный университет управления Москва, Россия

doi: 10.18411/lj-25-12-2016-3-07

idsp 000001:lj-25-12-2016-3-07

\section{Контроль расходов в организации с целью их снижения на пути к эффективной деятельности}

\section{Аннотация}

Расходы являются одним из важнейших факторов, влияющих на финансовые результаты организации, текущее финансовое состояние и долгосрочные планы развития в новых экономических условиях.Поэтому на пути к повышению эффективности производствав любой организации управление, контроль и снижение расходов занимает особое место в структуре управления предприятием.

Ключевые слова: контроль, планирование, оптимизация, анализ расходов; нормативный стандарт; эффективная деятельность; управление организацией.

\section{Blyablina D.A. \\ Cost control in the organization with the aim of reducing them on the way to efficient operation \\ State University of management Moscow}

\section{Abstract}

Costs are one of the most important factors affecting the financial results of the organization, current financial condition and long-term development plans in the new economic environment. So on the way to improving production efficiency in any organization, the management, control and cost reduction has a special place in the structure of enterprise management.

Key words: control, planning, optimization, cost analysis; normative standard; efficient operation; management of the organization.

Еще в начале прошлого века предприятиям удавалось управлять расходами за счет минимизации расходов, внедряя новые технологии, снижая накладные расходы и сокращая персонал. В связи с тем, что данные методы со временем 
перестали останавливать падение прибыли, предприятия стали использовать оптимизацию расходов, для этого была усилена роль контроля расходов в процессе управления организацией.

Контроль, как важнейшая функция управления расходами, распространяется не только на результат деятельности организации, но и на всю управленческую деятельность. Кроме того, в соответствии с п. 1 ст. 19 Федерального закона от 06.12.2011г. №402-Ф3 «О бухгалтерском учете» экономический субъект обязан организовать и осуществлять внутренний контроль совершаемых фактов хозяйственной жизни. [2]

Осуществление внутреннего контроля позволяет организациям выявить и оценить отклонения, постоянно осуществлять мониторинг работы в целях обоснованности и эффективности принятия управленческих решений, снижать риски деятельности организации.

Рассматривая контроль расходов, как процесс можно выделить 3 стадии:

- разработка нормативного стандарта расходов на единицу продукта (период времени);

- оценка фактических результатов в сопоставлении их со стандартами на предмет выявления отклонений;

- разработка мер в целях устранения негативных результатов или закрепления положительных.[1]

Нормативные стандарты расходов - это то сформированное количество расходовдля конкретной деятельности, которое рассматривается, как ожидаемый результат и которое стремятся достичь.

Для этого стандарты должны быть подтверждены расчетами, поддаваться количественной оценке, учитывать специфику условий и их изменений, быть достижимыми (реалистичными) и сопоставимыми.

При формировании норм расходов на предприятии необходимо определение реальных стандартов, которые отражали бы ту величину расходов, которые позволили бы предприятию сохранить имеющееся положение на рынке, которые базировались бына фактически существующих условиях производства, а не на теоретически идеальной производственной деятельности. Также необходимо определение идеальных стандартов, выступающих в качестве ориентира, которые могли бы быть достигнуты в оптимальных условиях производства и наиболее благоприятных ценах.

Далее оценка фактических результатов осуществляется путем сопоставления планируемых и фактических расходов. Эффективный контроль должен быть основан в первую очередь на прогнозируемых результатах, а не на фактических. Необходимо предсказывать вероятные события, на основе этих прогнозов заранее разрабатывать корректирующие действия и осуществлять те из них, которые будут необходимы. Это поможет привести фактические результаты к запланированным.[1]

Когда отклонения между фактическими расходами и нормами выявлены, руководитель принимает решение о проведении анализа отклонений и их причин. 
С целью эффективного управления организациейруководитель должен иметь на руках объективную, а не приукрашенную, информацию о своем предприятии. С этой целью сотрудниками проводится ряд следующих мероприятий:

- изучают факторы, влияющие на затраты;

- проверяют соответствие технологических процессов нормам, которые закладывались еще в период проектирования предприятия;

- рассчитывают оптимальную нагрузку производственных цехов;

- выясняют причины перерывов в работе;

- $\quad$ контролируют наличие сбоев при отгрузке или приемке товаров;

- выявляют затаривание склада и т.п.

Затем происходит анализ и оптимизация расходов, то есть сотрудникинамечают программу сокращения выявленных затрат, а руководитель рассматривает ее и утверждает, предварительно оценив риски, альтернативные решения и последствия изменений через год, два, пять лет.

В рамках анализа выявляются расходы важные, необходимые для развития и роста компании, нехватка финансирования которых может обернуться крахом предприятия, и те расходы, которые стоит пересмотреть.

Все стратегии снижения затрат утверждаются руководителем, они находят свое отражение в бюджете предприятия. Нарушать принятые решения можно только в исключительных случаях. За соблюдением этого правила должны отвечать финансовые службы. В их обязанность входит следить за обоснованностью расходов и отсекать ненужные траты.[3]

В рамках контроля, анализ и оптимизация затрат - это работа, которая не имеет даты окончания, она является ежедневной, планомерной и рутинной.

В заключении хотелось бы обратить внимание на то, что негативные тенденции мирового финансового кризиса, перешедшие уже в разряд экономического кризиса, привели к обострению финансово-экономического положения на предприятиях.В связи с чем, не разобравшись в источниках снижения прибыли и не уделив должного внимания изучению постоянных расходов организации, некоторые представители предприятий начинали панически снижать их. Данные действия, в свою очередь, привелик негативным стратегическим последствиям и тактическим потерям.Поэтому крайне важен грамотный подход.Необходимо сохранять бдительность и трезвость рассудка, изучив досконально каждый пункт расходов, оценивать необходимость их совершения, возможные альтернативы, источники возникновения расходов, принимая во внимание все возможные риски.Главное - хорошо все анализировать, продумывать и составлять четкий план действий.Так как при правильном подходе, практически все затраты можно «безболезненно» сократить так, что не пострадает ни производительность, ни качество. 


\section{Литература}

1. Кондраткова В.С., Прохоренко Ю.Б., Веретина Т.С. Контроль расходов организации как важнейший фактор повышения их эффективности//Социально-экономические явления и процессы. - 2015.Т10,№12. - С.23-27;

2. Ланцова А. Д. Организация системы внутреннего контроля расходов на оплату труда организации как необходимая составляющая эффективного управления // Молодой ученый. - 2014. - №4.2. - С. 99-101;

3. http://kupi-franshizu.ru/stati/1363-puti-optimizacii-i-snizhenie-rashodov-napredprijatii_jeffektivnost-snizhenija-zatrat.html 